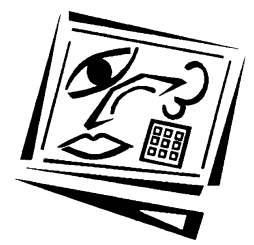

\title{
Cyberbullying and victimisation among Turkish university students
}

\author{
Yavuz Akbulut and Bahadir Eristi \\ Anadolu University
}

\begin{abstract}
This study investigated the extent of cyberbullying and victimisation among Turkish university students at a state college of education. A personal information form and 56 scaled items were administered to 254 students. Items addressing cyberbullying victimisation were adopted from a recent study, whereas parallel cyberbullying items were developed and piloted in the current study. High internal consistency coefficients and explained variance values were observed in both 'cyberbullying' and 'victimisation' forms of the instrument. Findings revealed a moderate relationship between cyberbullying and victimisation. That is, being a victim in the cyberspace predicted 23 percent of being a cyberbully. Males were more likely to be both cybervictims and cyberbullies. Neither the cyberbullying nor the victimisation average differed with regard to age, program of study, daily Internet use, language proficiency, socioeconomic status, and the location where Internet was used. Reasons to cyberbully were investigated, which were mostly stemmed from interpersonal problems of participants. Limitations were discussed followed by suggestions for further research.
\end{abstract}

\section{Introduction}

Bullying has been a topic of increasing concern for educators over the past decades (Chibbaro, 2007; Crawford, 2002). Defined as intentional and aggressive behaviour involving an imbalance of power and strength (Kowalski, Limber, \& Agatston, 2008), bullying has been considered a source of deep emotional damage on individuals (Anderson \& Sturm, 2007). Several interesting studies have been conducted on school bullying (e.g. Jacobson, 2010; Lee, 2010; Shore, 2009) and workplace bullying (e.g. Ferfolja, 2010; Lester, 2009; Roscigno, Lopez \& Hodson, 2009). While the issue needs constant research regarding the nature of bullying, emerging technologies have expanded the boundaries of bullying to the digital world, which created a new form named cyberbullying.

Cyberbullying can be defined as the deliberate use of electronic communication tools through which harm or disturbance is intentionally and repeatedly delivered, targeting a specific individual or group of individuals (Ang \& Goh, 2010; Patchin \& Hinduja, 2006). Willard (2005) classifies the ways cyberbullying occurs as flaming (angry or rude messages), harassment (recurring offensive messages), cyberstalking (threats of harm or intimidation), denigration (harmful, false, cruel statements), masquerade (pretending to be someone else to make that person look bad), outing (sharing others' private information), trickery (tricks to solicit embarrassing information), and exclusion (intentional exclusion from an online group). These actions 
can be conducted by anybody in the cyberspace. Anonymous users of different age groups attack victims of any age. Thus, cyberbullying and victimisation are not peculiar to a certain age group.

Theoretical work on cyberbullying usually suggests that harm is intended in cyberbullying. Cyberbullies have more power than the victims (McGrath, 2007), probably because of the anonymity involved in the cyberspace. That is, perpetrators can shield themselves through nicknames to hide their identities (Shariff, 2008). This anonymity makes cyberbullying even more prevalent and attractive to Internet users (Aricak, 2009). In addition to the anonymity of the bullies and the ease with which digital content can be transmitted, the lack of empathy increases the extent of cyberbullying, which stems from the fact that bullies cannot see the impact of their actions on the victims (Froese-Germain, 2008). In this regard, the digital world is an enormous and somewhat interminable platform for individuals to abuse others.

Since the victims are often hurt psychologically, cyberbullying can disrupt all aspects in the learners' lives (Feinberg \& Robey, 2008), so the society has began to move away from regarding such instances as a natural part of growing up to considering the serious psychological harm they may cause (Anderson \& Sturm, 2007). Empirical work has revealed a significant relationship between cyberbullying and emotional troubles (Hoff \& Mitchell, 2009; Juvonen \& Gross, 2008; Ybarra, Mitchell, Wolak \& Finkelhor, 2006). In addition, a significant relationship between perceived psychological vulnerability and achievement has been reported (Nishina, Juvonen \& Witkow, 2005). Therefore, cyberbullying may have the potential to interfere with the academic development of learners.

Studies administering online questionnaires (Akbulut, Sahin \& Eristi, 2010a; Juvonen $\&$ Gross, 2008) and those conducting face to face surveys like the current study (Hoff \& Mitchell, 2009; Li, 2008) have served as plausible resources of information regarding the prevalence of cyberbullying. For example, Juvonen and Gross (2008) administered an anonymous, web-based survey to 1454 participants aged from 12 to 17 years. The majority of the respondents ( $72 \%$ ) reported at least one cyberbullying incident, $85 \%$ of whom experienced bullying in school as well. School-based bullying predicted cyberbullying more than any particular e-communication tool, whereas both forms of bullying were associated with increased social anxiety. Li (2008) went a step further and conducted a cross-cultural comparison between two sets of data collected in Canada and China. Findings indicated similarities in terms of traditional bullying, but culture-specific differences in terms of cyberbullying. Regardless of the similarities and differences, the extent of instances indicated that cyberbullying has become a serious global problem.

The seriousness of this problem has been investigated in a recent study by Hoff and Mitchell (2009), who collected data from 351 undergraduate students through a survey containing limited choice, scaled, and open-ended questions. Cyberbullying was prevalent, affecting about $56 \%$ of the participants. Females reported significantly more instances of cyberbullying victimisation. Cyberbullying instances usually emerged from relationship problems like break-ups, envy, intolerance, and ganging up. Similar to the Juvonen and Gross (2008) study, negative effects on social well-being were reported. The serious finding was that 'reactive behavior from schools and students was generally inappropriate, absent or ineffective' (p.652). 
In addition to interpersonal problems indicated by Hoff and Mitchell (2009), victimisation can be the reason behind cyberbullying. Bauman (2010) studied 221 intermediate school students in a rural area of the Southwestern United States and found that the best predictor of cyberbullying was cybervictimisation, and vice versa. Cyberbullying and cybervictimisation were found strongly correlated in a relatively small special education setting as well (Bauman \& Pero, 2010). Walrave and Heirman (2011) questioned 1318 Belgian adolescents about their involvement in cyberbullying, which revealed that victims were more likely to exhibit cyberbullying behavior. Finally, König, Gollwitzer and Steffgen (2010) collected data from 473 students through an online survey of which 149 were identified as traditional victims and bullies. Findings revealed that bullied students tended to choose their former perpetrators as their cybervictims.

As suggested by Li $(2007,2008)$, culture specific differences in terms of cyberbullying could be observed. In this regard, addressing recent studies from Turkey was necessary to describe the research context. For instance, Erdur-Baker and Kavsut (2007) investigated instances of cyberbullying among two hundred twenty eight 14 to 19 year olds. Findings revealed that male students were more likely to be cyberbullies and victims. The frequency of Internet use correlated with both being a cyberbully and a cybervictim, whereas family income, school type, grades and age were not related with the target variables. Through administering the same data collection tool to one hundred eighty three 14 to 15 year olds, Topçu, Erdur-Baker and Çapa-Aydin (2008) examined cyberbullying among public and private school students. Interesting findings were observed with regard to cyberbullying behaviours of teenagers from different socio-economic backgrounds. Even though private school students used ecommunication tools more frequently, public school students reported more instances of being bullies and victims in cyberspace. In addition, private school students were less vulnerable to the negative experience as they thought it was a joke, whereas public school students reported as getting angry when faced with such instances. While discussing this difference, Akbulut et al. (2010a) maintained that cyberbullies and cybervictims from different socio-economic backgrounds could have different attitudes towards differentiating between the friendly banter and bullying, an interesting issue discussed by Sharif (2004) as 'teen talk'.

A recent study conducted with 695 Turkish undergraduate students supported the relationship between cyberbullying and anonymity (Aricak, 2009). Maintaining anonymity in cyberspace easily was found to be a facilitator of cyberbullying. In addition, hostility and psychoticism predicted cyberbullying at a statistically significant level. Males reported more instances of online impersonation. Half of the participants reported masquerading at least once while using e-communication tools. The study revealed that cyberbullying was not an issue peculiar to adolescence, but a problem extending to adulthood in Turkey. Similarly, Akbulut, Sahin and Eristi (2010b) expanded the subject matter beyond adolescence and administered a 28-item scale to 1470 Facebook users. Cyberbullying was quite prevalent among participants. In addition, gender, marital and socioeconomic status, Internet use frequency, and language proficiency were found to be significant predictors of cyberbullying victimisation. Firstly, males were more likely to be victims than females, but this difference varied according to the location where Internet was used. Specifically, females had more problems when they used Internet outside home, but fewer problems when they used Internet at home. Second, single participants reported more victimisation than married ones. Third, Internet use frequency and victimisation 
correlated significantly. Fourth, high income group had more victimisation problems. Finally, the more the users were proficient in a foreign language, the more victimisation problems they had, particularly because of visiting international websites more frequently. Several other variables were investigated in the study among which age, education level and Internet proficiency did not predict the extent of victimisation at a statistically significant level, which suggested that cyberbullying was equally prevalent among Facebook users regardless of these background variables.

If observed, potential differences in cyberbullying and victimisation with regard to the program of study and gender may be explained through occupational socialisation and gender socialisation theories. Gender socialisation theory suggests that women are more likely than men to obey rules; whereas, occupational socialisation theory implies that individuals at the same workplace are similar in outlook regardless of their genders (Adam, 2000; Mason \& Mudrack, 1996; Ward \& Beck, 1990). A recent work on computer ethics suggested that gender and occupational socialisation theories could interact (Akbulut, Uysal, Odabasi \& Kuzu, 2008). That is, gender socialisation theory might be valid in some occupations whilst invalid in some others. Females were more consistent in terms of perceived ethical computer use across different programs whereas males varied with regard to the program of study in the Akbulut et al. (2008) study. In this regard, both the program of study and gender were considered important variables to study while addressing ethical issues.

Even though cyberbullying has been cited among the top priority tech trends of contemporary technology and learning (McLester, 2008), a quick search in the ERIC database could only locate 101 instances of 'cyberbullying' (search date 16 October 2011). In this regard, the gap between the technological advances and the dearth of study on cyberbullying (Aricak et al., 2008) should urge researchers to conduct more research to improve the theoretical framework. The current study first aimed to see whether a recent cyberbullying victimisation scale developed for Facebook users (Akbulut et al., 2010a) worked for undergraduate students in a Turkish teaching training institution. In addition, development of a parallel cyberbullying form of the scale was realised. Then, the relationship between the 'cybervictim' and 'cyberbully' forms was examined. Next, background variables underlined in previous studies were examined with a reference to their influence on being a cyberbully and a cybervictim. Finally, reported reasons of cyberbullying were listed along with descriptive statistics. Note that traditional bullying was not investigated in the current study. Throughout the following pages, the term victim referred to the cyberbullying victim whereas the term bully referred to the cyberbully.

\section{Methods and procedures}

\section{Participants}

The research context was one of the privileged, recognised, and respected Turkish colleges of education according to the national rankings. Participants of the study were junior students (i.e. 3rd year) with age ranging from 18 to 23 years. Older students, who were more likely to reflect the characteristics of the teaching profession, were deliberately selected so that the occupational socialisation theory could be tested better. In this regard, freshmen and sophomores (i.e. 1st and 2nd years) were not included in the sample. On the other hand, because of the apprenticeship responsibilities outside the school, senior students (i.e. 4th year) were not accessible. 
During the final week of a requried course for juniors - Educational Measurement eight out of 16 classes were selected randomly and informed about the study. As the subject matter was quite a delicate one, voluntary participation was emphasised. Of 383 students in eight classes, 267 responded voluntarily $(69.71 \%)$. However, 13 questionnaires $(4.9 \%)$ were eliminated because most questions were not answered, or answered with the same monotonous pattern. In brief, the number of valid questionnaires $(n=254)$ constituted 33 percent of the whole junior student population $(\mathrm{n}=776)$. Of respondents, $173(68.11 \%)$ were females, $73(28.74 \%)$ were males, and eight participants $(3.15 \%)$ did not indicate their genders. The sample was further examined according to the distribution of males and females. The sample distribution was compared with that of the junior student population $\left(\chi^{2}=0.058 ; \mathrm{p}=0.810\right)$ and that of whole college population $\left(\chi^{2}=0.124 ; p=0.725\right)$ through one-sample chi-square tests, which indicated that the distribution of the sample with regard to gender was almost identical with the target populations.

Different programs of study were represented in the sample. Thirty five participants from art education $(13.8 \%), 31$ from computer education $(12.2 \%), 20$ from French language teaching (7.9\%), 19 from German language teaching (7.5\%), 97 from English language teaching $(38.2 \%), 19$ from social studies education $(7.5 \%)$, and 33 from mathematics education $(13.0 \%)$ constituted the whole sample. Further analyses revealed that the distributions of different programs of study in the sample were quite similar to their distributions in the target population, except for over-representation from English language teaching. While the students in the program represented 25 percent of the whole college, the current sample had 38 percent of participants from that program. Collecting additional data from further classrooms to increase the proportion of other groups was not possible, whereas randomly excluding some questionnaires from the over-represented group was not considered ethical. Probably, voluntary participation interfered with the desired ideal distribution. Hence, this situation could be considered as a limitation in terms of the sample representativeness.

\section{The instrument}

The instrument was developed and administered in Turkish. A personal information form was followed by 56 Likert items. Half of the items were related to 'being a cyberbully' whilst the other half addressed 'being a cybervictim'. The form included background variables such as gender, program of study, age, Internet use location and frequency, foreign language proficiency and socio-economic status. Likert items addressing cyberbullying victimisation were adopted from a recent study (Akbulut et al., 2010a), which realised the construct validation through two pilot studies. Items were particularly designed to investigate individuals' recent online communication experiences involving cyberbullying victimisation. Instances of flaming, harassment, cyberstalking, denigration, masquerade, exclusion, outing and trickery were included in the scale. In order to reduce the likelihood of committing a self-selection bias, the term 'cyberbullying' was never used explicitly as suggested by Juvonen and Gross (2008). The frequency of victimisation was investigated on 5-item scales: never, rarely, sometimes, often and always, referred to 1, 2, 3, 4, and 5. Administrations in the original study revealed a 28 -item set with a single-factor structure, and explained half of the total variance with a high internal consistency coefficient $(\alpha=0.96)$.

The 'cybervictim' form developed by Akbulut et al. (2010a) was extended in a way to seek for 'cyberbullies' in the current study. That is, a cyberbullying item was prepared for each victimisation item. For instance, the item in the original victimisation scale, 
'Receiving harassing emails or instant messages', was rephrased as 'Sending harassing emails or instant messages' for the cyberbullying version. All items were modified for a cyberbullying version and checked by two reviewers to see whether the transformations revealed the real action of the cyberbully for each action. The form was piloted with 27 undergraduate students to check for potential misunderstandings and revised accordingly. The internal consistency coefficient for the pilot was 0.84, which was acceptable (Huck, 2008; Özdamar, 2004; Pallant, 2001).

\section{Data collection and analysis}

The instrument was administered to junior students during the last two weeks of the 2010 spring semester. In addition to the written instructions ensuring students about the confidentiality of the findings, the same instructions were given to participants in all classrooms to minimise researcher bias. The data were transferred to the electronic environment, checked for incorrect or missing values, and analysed through SPSS 15.0 for Windows. Internal consistency coefficients were checked, exploratory factor analyses were conducted, item descriptives were provided, the relationship between cyberbullying victimisation and cyberbullying was examined, and comparisons with regard to background variables were done through relevant parametric tests.

\section{Findings}

\section{Data collection tool}

The internal consistency coefficient for the victimisation scale was 0.94 , whereas that of the cyberbullying version was 0.95, suggesting ideal internal consistency (Field, 2005; Huck, 2008; Özdamar, 2004; Pallant, 2001). The data were divided according to the levels of the background variables (e.g. gender, program of study, age) to see the internal consistency coefficients with regard to those levels. Neither the victimisation nor the cyberbullying version had low internal consistency coefficients in these inspections (i.e. the lowest one was 0.86), that is, the internal consistency coefficients were high and stable among the levels of the background variables.

The majority of inter-item correlations were between 0.20 and 0.40 which were considered sufficient (Briggs \& Cheek, 1986). Corrected item-total correlations were considered acceptable according to the threshold of 0.30 (Pallant, 2001), as values ranged between 0.40 and 0.68 with an average of 0.59 for the victimisation form, whereas they ranged between 0.62 and 0.81 with an average of 0.64 for the cyberbullying form. Kaiser-Meyer-Olkin measures of sampling adequacy of 0.93 (victimisation) and 0.92 (cyberbullying) indicated perfect values (Hutcheson \& Sofroniou, 1999). These suggested that the sample size was sufficient, relationships among items were clear and the factor analyses could lead to reliable results (Field, 2000).

The single factor structure previously suggested in the Akbulut et al. (2010a) study explained 40 percent of the total variance in the current administration of the victimisation form whereas 47 percent was explained in the cyberbullying form. In social sciences, explained variance from 40 through 60 percent can be regarded as sufficient (Dunteman, 1989). Regarding the single factor structure in the current scales, explained variances were considered plausible. In both factor analyses, even the lowest item loads were above 0.40 , which was robust considering the 0.32 threshold (Worthington \& Whittaker, 2006). 


\section{Item descriptives}

In order to provide the findings in a concise way, a mutual wording for the victimisation and the cyberbullying versions was sustained in the current manuscript. Longer statements were used in the original Turkish scales with active (cyberbullying) and passive (victimisation) forms of the constructs provided in Table 1. A verbatim translation from Turkish to English for the cyberbullying victimisation form is available in Akbulut et al. (2010a).

Table 1: Descriptives of scale items

\begin{tabular}{|c|c|c|c|c|}
\hline \multicolumn{2}{|c|}{ Victim } & \multirow{2}{*}{ Behaviour } & \multicolumn{2}{|c|}{ Bully } \\
\hline Mean & SD & & Mean & SD \\
\hline 2.46 & 1.01 & Harassing emails / instant messages & 1.20 & 0.59 \\
\hline 1.51 & 0.79 & $\begin{array}{l}\text { Mocking in online social utilities about physical appearance, character } \\
\text { or an instance experienced }\end{array}$ & 1.34 & 0.64 \\
\hline 2.14 & 1.13 & Invitation to applications including gossips or inappropriate chat & 1.49 & 0.78 \\
\hline 1.78 & 0.95 & $\begin{array}{l}\text { Instant messages or emails including incorrect or bad things about } \\
\text { friends }\end{array}$ & 1.19 & 0.58 \\
\hline 1.51 & 0.84 & Incorrect and mean-spirited things written about a person & 1.29 & 0.70 \\
\hline 1.53 & 0.84 & $\begin{array}{l}\text { Experiencing problems because personal information is shared online } \\
\text { without consent }\end{array}$ & 1.16 & 0.53 \\
\hline 1.53 & 0.84 & Tricks to get personal information and publish it on the web & 1.16 & 0.50 \\
\hline 1.54 & 0.82 & $\begin{array}{l}\text { Publication of personal information through emails or instant } \\
\text { messaging tools without consent }\end{array}$ & 1.14 & 0.47 \\
\hline 1.48 & 0.88 & Exclusion from an online group / chat room & 1.40 & 0.79 \\
\hline 1.60 & 0.88 & Blocking / being blocked in instant messaging programs & 1.65 & 0.91 \\
\hline 2.26 & 1.22 & Messages imposing religious or political views & 1.43 & 0.86 \\
\hline 1.38 & 0.79 & Threatening emails or instant messages & 1.20 & 0.65 \\
\hline 1.46 & 0.79 & Use of personal information without consent & 1.18 & 0.58 \\
\hline 1.67 & 0.91 & Suffering from / using software aiming to get personal information & 1.23 & 0.59 \\
\hline 1.43 & 0.76 & Insulting emails or instant messages & 1.17 & 0.56 \\
\hline 1.49 & 0.81 & Publication of personal photographs and videos without consent & 1.16 & 0.50 \\
\hline 1.97 & 1.03 & $\begin{array}{l}\text { Disturbance in the instant messaging programs by those one does not } \\
\text { want to chat with }\end{array}$ & 1.18 & 0.53 \\
\hline 1.64 & 0.89 & Deception by people / tricking by pretending to be someone else & 1.30 & 0.68 \\
\hline 1.80 & 1.03 & Losing passwords or changing them because of password thieves & 1.22 & 0.55 \\
\hline 1.50 & 0.89 & $\begin{array}{l}\text { Using one's nickname without their knowledge and speaking on their } \\
\text { behalf }\end{array}$ & 1.18 & 0.57 \\
\hline 2.14 & 1.19 & Obscene emails & 1.12 & 0.49 \\
\hline 2.04 & 1.05 & Unwanted content without consent & 1.11 & 0.48 \\
\hline 2.15 & 1.19 & Cursing or slang language while using instant messaging programs & 1.40 & 0.80 \\
\hline 1.39 & 0.84 & Use of Webcam images without consent & 1.13 & 0.49 \\
\hline 1.56 & 0.96 & Obscene images while using the Webcam & 1.08 & 0.39 \\
\hline 1.80 & 1.01 & Proposals with sexual allusion & 1.11 & 0.42 \\
\hline 1.84 & 1.15 & Pressure to vote for or sign in a religious, political or sports group & 1.18 & 0.51 \\
\hline 2.10 & 1.10 & Hiding identities while communicating & 1.34 & 0.76 \\
\hline 1.74 & 0.59 & Average of all items & 1.24 & 0.41 \\
\hline
\end{tabular}

As indicated through the averages of all items, the extent of victimisation was larger than that of cyberbullying with a large effect size $\left(\mathrm{t}_{(253)}=14.87 ; \mathrm{p}<0.001 ; \eta^{2}=.47\right)$. In the current data codebook 1 meant 'never' and 5 meant 'always'. In this regard, means could be regarded as low. However, frequency distribution of items suggested that the least reported instance of victimisation - receiving threatening emails/instant messages - was experienced at least once by 24.1 percent of participants. When the 
frequency distribution of all victimisation items were considered one by one, the extent of rarely experienced victimisation instances ranged from 24.1 percent (threatening emails/instant messages) to 81.1 percent (harassing emails/instant messages). That is, the means were mathematically low but practically high when the psychological damage caused by the addressed behaviours was considered.

The most frequent instances of victimisation were receiving harassing emails or instant messages $(81.1 \%)$, receiving messages with religious or political content $(63.9 \%)$, being invited to social applications including gossips or inappropriate chat $(63.5 \%)$, confronting with cursing or slang language while using instant messaging programs $(61.8 \%)$, receiving obscene emails $(61.8 \%)$, confronting with addressees hiding identities while communicating $(61.7 \%)$, and receiving unwanted content without the receiver's consent $(61.4 \%)$. Percentages in parentheses indicated the proportion of those who experienced the specified behaviours at least 'rarely' or more frequently.

In terms of the cyberbullying variable, the most frequent instances were blocking in instant messaging programs (42.8\%), inviting people to social applications including gossips or inappropriate chat $(34.7 \%)$, sending messages imposing religious or political views $(25.6 \%)$, cursing or resorting to slang language while using instant messaging programs $(25.8 \%)$, excluding people from online groups $(25 \%)$, and hiding identity $(21.6 \%)$. Similar to the above analysis, percentages indicated the proportion of the participants who have conducted that specific type of cyberbullying at least 'rarely'. As seen in this pattern, some of these behaviours were not direct instances of cyberbullying. Rather, they could be considered as ways of defending oneself against cyberbullies. In the desired picture of the cyberspace, none of these instances should be experienced. However, the variable with the lowest mean in the current study showing obscene images while using a webcam - was reported by 14 participants $(5.5 \%)$ and 11 of those were males!

\section{Relationship between cyberbullying and victimisation}

Nonparametric correlations among victimisation and cyberbullying versions of 28 items revealed that only three items did not lead to a significant relationship between the two forms: disturbance in the instant messaging programs by those one does not want to chat with, messages with religious or political content, and harassing emails or instant messages. Except for these, all items led to significant relationships between the victimisation and cyberbullying instances at a probability value below 0.05 while 21 of these were significant at a probability value below 0.001 . In other words, 25 of 28 instances in the scale were behaviours where there was a relationship between being a victim and being a bully in the cyberspace.

The correlation between the cyberbullying and victimisation averages $(r=0.48)$ was quite significant for both males $(\mathrm{r}=0.48)$ and females $(\mathrm{r}=0.47)$ at a probability value below 0.001. A simple regression analysis with the cyberbullying variable as the criterion and the victimisation variable as the predictor was conducted. Findings revealed that cyberbullying victimisation explained 23 percent of the variability in the criterion variable of cyberbullying (adjusted $\mathrm{R}^{2}=.225, \mathrm{~F}=73.065, \mathrm{p}<.001$ ). Considering that the highest average for an ultimate cyberbully can be 5 in the current scale, the following regression equation evolving from the current model could be helpful for further implementations: Cyberbullying [Participant $\mathrm{A}]=0.658+(0.335 \times$ Cyberbullying victimisation $\left._{[\text {Participant A] }}\right)$. 


\section{Influence of the background variables}

Several one-way between-groups ANOVAs were conducted to see the influence of potential background variables on both cyberbullying victimisation and cyberbullying averages: program of study, daily Internet use, age, foreign language proficiency, socio-economic status, and the location of Internet use. Neither the victimisation nor the cyberbullying variable differed according to these background variables at a probability value of 0.05 or below. However, gender served as a significant predictor of both victimisation and cyberbullying as expected. Table 2 summarises the independent samples t-tests conducted to compare males and females with regard to their victimisation and cyberbullying averages. As indicated, males were significantly more likely to be both cyberbullying victims and cyberbullies. The effect size values (eta squared: $\eta^{2}$ ) could be interpreted as medium effect (Cohen, 1988; Huck, 2008).

Table 2: Comparison of males and females

\begin{tabular}{|l|l|c|c|c|c|c|c|c|}
\hline \multicolumn{1}{|c|}{ Variable } & Gender & $\mathrm{N}$ & Mean & $\mathrm{SD}$ & $\mathrm{df}$ & $\mathrm{t}$ & $\mathrm{p}<$ & $\eta^{2}$ \\
\hline Victimisation & Female & 173 & 1.63 & 0.53 & 244 & -4.38 & 0.001 & 0.073 \\
\cline { 2 - 8 } & Male & 73 & 1.97 & 0.61 & & & & \\
\hline \multirow{2}{*}{ Bullying } & Female & 170 & 1.16 & 0.31 & 241 & -4.87 & 0.001 & 0.09 \\
\cline { 2 - 7 } & Male & 73 & 1.43 & 0.55 & & & & \\
\hline
\end{tabular}

Considering the effect size, it could be suggested that gender - on its own - explained 9 percent of the variability in cyberbullying. In the simple regression provided above, victimisation explained 23 percent of the variability in cyberbullying. When the given simple regression was further improved through a hierarchical method where gender was a dummy variable in the analysis, the combined prediction power could be examined. Such a procedure revealed that after 25.1 percent variability explained by victimisation was controlled, gender could create an additional three percent change $\left(R^{2}\right.$ change $\left.=0.029\right)$. The variability explained by the victimisation variable changed here because the nature of the analysis and the number of variables changed. Anyway, the victimisation variable explained the significant amount in the cyberbullying variable whereas the prediction power of gender was practically trivial, but statistically significant $(\mathrm{p}<0.05)$. Therefore, the researchers suggest using the regression equation provided above until larger scale implementations have been conducted to diagnose subsequent sources of the variance in the cyberbullying variable.

\section{Reasons to cyberbully}

Of 254 participants, 179 participants (70\%) mentioned their reasons to bully. Researchers listed several reasons for cyberbullying and six of those were particularly chosen by participants. As provided in Table 3, a considerable amount was related to interpersonal problems with the addressee. Bearing a grudge against somebody and to irritate somebody added up to 52 percent. When taking revenge and being a victim before were examined together - as both were types of cyberbullying as response to a previous victimisation - percentages of both added up to 25 percent. Satisfying the thirst for imposing political and religious views constituted a small portion of the whole comments. Regarding the recent political transformations observed in Turkey, this percentage was not a surprise. The serious percentage belonged to those who bullied one another without a specific reason. 
Table 3: Reported reasons to cyberbully

\begin{tabular}{|l|c|c|}
\hline \multicolumn{1}{|c|}{ Reason } & $\mathrm{f}$ & $\%$ \\
\hline Bearing a grudge against somebody & 68 & 35.8 \\
\hline There is not a specific reason & 37 & 19.5 \\
\hline To irritate someone & 31 & 16.3 \\
\hline Been a cyber-victim before & 29 & 15.2 \\
\hline To take revenge & 19 & 10.0 \\
\hline To impose political / religious views & 6 & 3.2 \\
\hline Total & 190 & 100 \\
\hline
\end{tabular}

\section{Discussion}

Findings regarding the internal consistency of the scales along with exploratory factor analyses revealed that both the previously developed victimisation version and the cyberbullying version generated in the current study worked well for Turkish participants in a teacher training institution. However, the essence of the items might be lost during translations from Turkish to English or some items may work differently in different cultures. Thus, further implementers from international settings can try to modify the current list of cyberbullying behaviours according to their unique contexts and cultures, since cultural differences in terms of cyberbullying were reported ( $\mathrm{Li}$, $2007,2008)$. Such an eclectic attitude - adding culture specific bullying instances to those illustrated in the literature - should help researchers to explain a higher degree of variance in the constructs of cyberbullying and victimisation.

Some items in the current scale may not be classified as cyberbullying in different contexts or in Western countries such as the unwanted messages with religious or political content, or excessively slang language in online interactions. Further discussions on the nature of current items and their inclusion criteria in the cyberbullying scale can be found in Akbulut et al. (2010a). However, it is indicated beforehand that individuals with different backgrounds can have different attitudes in terms of differentiating between the friendly banter, aggressive behaviour and bullying. If harm is intentionally and repeatedly delivered through ICTs targeting a specific group or individual (Ang \& Goh; Patchin \& Hinduja, 2006), listed behaviours may all be instances of cyberbullying. However, the instances may vary among different cultures. Recent research indicates that different countries and cultures may behave differently regarding bullying involvements, as individuals may hold different beliefs or religions predicting their behaviours (Li, 2007, 2008).

Descriptive statistics regarding individual items revealed that cyberbullying and victimisation were prevalent among university students, which retained previous findings (Arıcak, 2009). The difference between victimisation and cyberbullying scores was expected, but the magnitude of the difference might not be that much. It was possible that participants responded in accordance with the social desirability in such a subject. That is, they might have under-reported their cyberbullying behaviors. If the term 'cyberbullying' had been used explicitly in the data collection tool, the degree of bullying confessions might have been even lower.

Both nonparametric correlations among each victimisation and bullying item, and the simple regression conducted with the averages, revealed a mutual variance between victimisation and bullying as indicated in the previous literature (Bauman, 2010; Bauman \& Pero, 2010; Walrave \& Heirman, 2011). The correlation between the 
cyberbullying and victimisation averages led researchers to conduct a simple regression, which indicated that approximately one fourth of bullying was explained merely by victimisation. Considering the enormity of the explained variance, one could even suggest that one fourth of every victim group can become a bully in future! The finding retained the argument of $\mathrm{Li}$ (2006) about the existence of bully victims students who become bullies after being victimised. By any means, the regression equation evolved in the current study should be further developed through large scale administrations. The extent of cyberbullying is somewhat hard to measure since participants are likely not to respond honestly because of the social desirability concerns. Thus, the regression equations, which can predict the extent of cyberbullying through the extent of victimisation and through other proven predictors, may be plausible since it is easier and less face threatening to administer the victimisation scales.

Except for gender background, variables underlined in previous studies did not have a predictive power on the extent of either cyberbullying or victimisation. Family income and age did not influence the target variables as reported (Erdur-Baker \& Kavsut, 2007). On the other hand, the Erdur-Baker and Kavsut (2007) study suggested a predictive power for the frequency of Internet use which was not retained in the current case. In addition, the influence of socio-economic status reported in the Topçu et al. (2008) study was not observed. Occupational socialisation theory discussed in the introduction did not apply, as variables did not differ across different programs of study. Refuting the findings of Akbulut, Sahin and Eristi (2010b), foreign language proficiency and the location of Internet use were not significant predictors of the target variables. Participants in the current study were being educated to be an educator. In such a homogeneous group, influences of previously discussed background variables may have been suppressed by the power of education. Maybe, self-confident and socially active university students, who were more likely to be responsible and democratic citizens, had a higher chance for free speech and are less influenced by implied coercion while reflecting their identities. In this regard, university freedom might have created 'background variable-proof' individuals. Qualitative inquiries are urgently needed to support this intuition.

The significant relationship between victimisation and bullying, and differences between males and females with regard to cyberbullying and victimisation could suggest that there was a bullying loop, which was mostly activated by males in contrast with the findings of some studies (Hoff \& Mitchell, 2009; Patchin \& Hinduja, 2006), and in line with many others (Arıcak, 2009; Aricak et al., 2008; Erdur-Baker \& Kavsut, 2007; Li, 2006). Probably, male fight creates both victims and new bullies: the pitcher goes to the well so often that it is broken at last. In addition, Turkey is a patriarchal society to a considerable extent in which dominance of men in social or cultural endeavours is relatively apparent. Females in Turkey are more likely and expected to obey the rules of the society as indicated in the gender socialisation theory. In this regard, the male-female dichotomy in terms of cyberbullying should be investigated in different cultural backgrounds as well. Further research is needed to understand the interaction patterns of bullies to be sure of such interpretations.

Reported reasons for cyberbullying indicated that bullies mostly had interpersonal problems with the victims. Sometimes, they were victimised by someone who urged them to cyberbully. When they were able to hide their identities in the digital world, they counter attacked. The distribution of the reasons could be considered parallel to 
the findings of Hoff and Mitchell (2009) maintaining that cyberbullying emerged mostly from interpersonal problems (e.g. envy, intolerance). Findings of the study by König et al. (2010) were also in accord, as victimised students tend to be cyberbullies after the unpleasant instance. Still, there were people who bullied others without a specific reason. These participants could be in the real bully group who gained satisfaction from hurting others and who had a really strong need to dominate (Diamanduros, Downs \& Jenkins, 2008). This particular group should be further examined and the underlying reasons behind their actions should be investigated.

As indicated beforehand, there were few studies on cyberbullying and most of these addressed adolescents. However, cyberbullying could be an issue apparent in all age levels. To be a school bully, it is usually necessary to be a classmate or schoolmate of the victim. However, in order to be a cyberbully, computer and Internet literacy is sufficient. Any literate individual who can use a webcam, sign into email services with a fake profile, send instant messages or emails, reply to messages and upload files can conduct behaviours listed in the current scale. They can even find out about more complicated ways to cyberbully others through a simple search on the Internet. The perpetrators may be at any age or education level as the victims cannot see them. That is, cyberbullying is not an adolescent misconduct, but an issue that could be apparent in any age, education and socio-economic level. Therefore, it should probably be investigated within the framework of lifelong learning in future research endeavours. Moreover, current findings should be interpreted by school counselors, classroom teachers and administrators in a way to prevent cybervictimisation instances in schools. Sample intervention strategies and precautions to address bullying in schools can be found in recent studies (e.g. Cross, Monks, Campbell, Spears \& Slee, 2011; Diamanduros et al., 2008; Hope, 2010) and legal precautions can be taken into account (e.g. Butler, Kift \& Campbell, 2009; Kift, Campbell \& Butler, 2010).

The current study poses several limitations. Even though the current scale addressed many cyberbullying instances in a reliable way, it only had one dimension. Moreover, some items may be regarded as culture or context specific. Thus, new scales with elaborated factor structures may be used to replicate the current findings (e.g. Çetin, Yaman \& Peker, 2011). On the other hand, the construct of cyberbullying is still new and relatively ill-defined for the time being. In addition, the social desirability bias, i.e. participants' tendency to respond in a way that will be favoured by others is on the stage. In this regard, scale development and validation endeavours in different contexts should continue.

Small sample size and the homogeneity of the group can be listed among the limitations of the current study as well. Large-scale administrations among both high school and university students should follow the current study. In addition, even though the conservative educational system of the current research context creates observable behaviour differences among different programs of study, it was somewhat insufficient to test the occupational socialisation theory with university students who are not completely socialised into jobs. Next, a quantitative approach was primarily followed in the current study. However, current findings should be supported through qualitative inquiries in future research endeavours. Further research can also focus on the interaction patterns of the victims and bullies since there are still few studies on such issues. How do victims react to cyberbullying? How do they fight against? With whom do victims and bullies interact? In this regard, discussion forum data can be analysed and overt victims can be further studied through detailed case studies. 
Finally, the effects of different fanaticisms on bullying can be investigated such as sports, radical religious and political wings, and racism. Such studies should help scholars to define the construct better, and generate more robust solutions to the problems stemming from cyberbullying.

\section{References}

Adam, A. (2000). Gender and computer ethics. Computers and Society, 30(4), 17-24. http: / / dl.acm.org/ citation.cfm?doid=572260.572265

Akbulut, Y., Sahin, Y. L. \& Eristi, B. (2010a). Development of a scale to investigate cybervictimization among online social utility members. Contemporary Educational Technology, 1(1), 46-59. http: / / cedtech.net/articles/114.pdf

Akbulut, Y., Sahin, Y. L. \& Eristi, B. (2010b). Cyberbullying victimization among Turkish online social utility members. Educational Technology \& Society, 13(4), 192-201. http: / / www.ifets.info/journals/13_4/17.pdf

Akbulut, Y., Uysal, O, Odabasi, H. F., \& Kuzu, A. (2008). Influence of gender, program of study and PC experience on unethical computer using behaviors of Turkish undergraduate students. Computers $\mathcal{E}$ Education, 51(2), 485-492. http: / / dx.doi.org/10.1016/j.compedu.2007.06.004

Anderson, T. \& Sturm, B. (2007). Cyberbullying: From playground to computer. Young Adult Library Services, 5(2), 24-27.

http://www.ala.org/ala/mgrps/divs/yalsa/yalsapubs/yals/5n2/5n2.cfm

Ang, R. P. \& Goh, D. H. (2010). Cyberbullying among adolescents: The role of affective and cognitive empathy, and gender. Child Psychiatry and Human Development, 41(4), 387-397. http: / / www.springerlink.com/ content/m055863451520vj2/

Aricak, O. T. (2009). Psychiatric symptomatology as a predictor of cyberbullying among university students. Egitim Arastirmalari - Eurasian Journal of Educational Research, 34, 167-184. http: / / www.ejer.com.tr / index.php?git=22\&kategori=66\&makale $=618$

Aricak, T., Siyahhan, S., Uzunhasanoglu, A., Saribeyoglu, S., Ciplak, S., Yilmaz, N. \& Memmedov, C. (2008). Cyberbullying among Turkish adolescents. CyberPsychology $\mathcal{E}$ Behavior, 11(3), 253-261. http: / / www.liebertonline.com/doi/pdfplus/10.1089/cpb.2007.0016

Bauman, S. (2010). Cyberbullying in a rural intermediate school: An exploratory study. The Journal of Early Adolescence, 30(6), 803-833. http: / / jea.sagepub.com/content/30/6/803

Bauman, S. \& Pero, H. (2010). Bullying and cyberbullying among deaf students and their hearing peers: An exploratory study. Journal of Deaf Studies and Deaf Education, 16(2), 236-253. http: / / jdsde.oxfordjournals.org/content/16/2/236.short?rss=1

Briggs, S. R. \& Cheek, J. M. (1986). The role of factor analysis in the development and evaluation of personality scales. Journal of Personality, 54(1), 106-148.

http: / / onlinelibrary.wiley.com/ doi/10.1111/j.1467-6494.1986.tb00391.x/abstract

Butler, D. A., Kift, S. M. \& Campbell, M. A. (2009). Cyber bullying in schools and the law: Is there an effective means of addressing the power imbalance? eLaw Journal, 16(1), 84-114. https: / / elaw.murdoch.edu.au/index.php/elawmurdoch/article/view/24/8

Çetin, B., Yaman, E. \& Peker, A. (2011). Cyber victim and bullying scale: A study of validity and reliability. Computers \& Education, 57(4), 2261-2271. http: / / www.sciencedirect.com/ science/ article/ pii / S0360131511001436 
Chibbaro, J. S. (2007). School counselors and the cyberbully: interventions and implications. Professional School Counseling; 11(1), 65-67.

http: / / schoolcounselor.metapress.com/content/h20g14660446463g/

Cohen, J. W. (1988). Statistical power analysis for the behavioral sciences (2nd ed). Hillsdale, NJ: Lawrence Erlbaum Associates.

Crawford, N. (2002). New ways to stop bullying. Monitor on Psychology, 33(9), 64. http://www.apa.org/monitor/oct02/bullying.aspx

Cross, D., Monks, H., Campbell, M. A., Spears, B. \& Slee, P. (2011). School-based strategies to address cyber bullying. Occasional Papers (119). Centre for Strategic Education, Melbourne, Vic. http:/ / eprints.qut.edu.au/41318/

Diamanduros, T., Downs, E. \& Jenkins, S. J. (2008). The role of school psychologists in the assessment, prevention, and intervention of cyberbullying. Psychology in the Schools, 45(8), 693-704. http: / / onlinelibrary.wiley.com/doi/10.1002/pits.20335/abstract

Dunteman, G. H. (1989). Principal component analysis. Quantitative applications in the social sciences series (vol. 69). Thousand Oaks, CA: Sage Publications.

Erdur-Baker, Ö. \& Kavsut, F. (2007). Cyber bullying: a new face of peer bullying. Egitim Arastirmalari-Eurasian Journal of Educational Research, 27, 31-42. http: / / www.ejer.com.tr/index.php?git=archives\&categori $=62$

Feinberg, T. \& Robey, N. (2008). Cyberbullying. Principal Leadership, 9(1), 10-14. http:/ / online.qmags.com/PLA0908/

Ferfolja, T. (2010). Lesbian teachers, harassment and the workplace. Teaching and Teacher Education: An International Journal of Research and Studies, 26(3), 408-414. http: / / www.sciencedirect.com/science/article/pii/S0742051X09001206

Field, A. (2000). Discovering statistics using SPSS for Windows. London: Sage Publications.

Field, A. (2005). Discovering statistics using SPSS (2nd edition). London: Sage Publications.

Froese-Germain, B. (2008). Bullying gets digital shot-in-the-arm. Education Canada, 48(4), 44-47. http:/ / www.ctf-fce.ca/publications/pd_newsletter/PD2009_Volume8-2English_Article6.pdf

Gross, E. F. (2004). Adolescent Internet use: What we expect, what teens report. Journal of Applied Developmental Psychology, 25(6), 633-649. http:// www.sciencedirect.com/ science/article/ pii/S0193397304000772

Hoff, D. L. \& Mitchell, S. N. (2009). Cyberbullying: causes, effects, and remedies. Journal of Educational Administration, 47(5), 652-665. http: / / www.emeraldinsight.com/journals.htm?articleid=1812293\&show=html

Hope, A. (2010). Seductions of risk and school cyberspace. Australasian Journal of Educational Technology, 26(5), 690-703. http: / / www.ascilite.org.au/ajet/ajet26/hope.html

Huck, S. W. (2008). Reading statistics and research (5th ed). Boston: Pearson.

Hutcheson, G. \& Sofroniou, N. (1999). The multivariate social scientist. London: Sage.

Jacobson, R. B. (2010). A place to stand: Intersubjectivity and the desire to dominate. Studies in Philosophy and Education, 29(1), 35-51.

http: / / www.springerlink.com/ content/lh0426268g160205/

Juvonen, J. \& Gross, E. F. (2008). Extending the school grounds?-Bullying experiences in cyberspace. Journal of School Health, 78 (9), 496-505.

http:/ / onlinelibrary.wiley.com/doi/10.1111/j.1746-1561.2008.00335.x/ full 
Kift, S. M., Campbell, M. A. \& Butler, D. A. (2010). Cyberbullying in social networking sites and blogs: Legal issues for young people and schools. Journal of Law, Information and Science, 20(2), 60-97. http:/ / eprints.qut.edu.au/39838/

Kowalski, R. M., Limber, S. P. \& Agatston, P. W. (2008). Cyberbullying: Bullying in the digital age. Malden, MA: Blackwell Publishing.

König, A., Gollwitzer, M., \& Steffgen, G. (2010). Cyberbullying as an act of revenge? Australian Journal of Guidance \& Counselling, 20(2), 210-224. http:/ / www.atyponlink.com/AAP/doi/abs/10.1375/ajgc.20.2.210

Lee, C. (2004). Preventing bullying in schools: A guide for teachers and other professionals. London: Paul Chapman Publishing.

Lee, C. H. (2010). Personal and interpersonal correlates of bullying behaviors among Korean middle school students. Journal of Interpersonal Violence, 25(1), 152-176. http: / /jiv.sagepub.com/content/25/1/152.short

Lester, J. (2009). Not your child's playground: Workplace bullying among community college faculty. Community College Journal of Research and Practice, 33(5), 446-464. http: / / www.tandfonline.com/doi/abs / 10.1080/10668920902728394

Li, Q. (2006). Cyberbullying in schools: A research of gender differences. School Psychology International, 27(2), 157-170. http:/ / spi.sagepub.com/ content/27/2/157.short?rss=1\&ssource=mfc

Li, Q. (2007). Bullying in the new playground: Research into cyberbullying and cyber victimisation. Australasian Journal of Educational Technology, 23(4), 435-454. http: / / www.ascilite.org.au/ajet/ajet23/li.html

Li, Q. (2008). A cross-cultural comparison of adolescents' experience related to cyberbullying. Educational Research, 50(3), 223-234. http: / / www.tandfonline.com/ doi/abs/10.1080/00131880802309333

Mason, E. S. \& Mudrack, P. E. (1996). Gender and ethical orientation: A test of gender and occupational socialization theories. Journal of Business Ethics, 15(6), 599-604. http:/ / www.springerlink.com/ content/n6u1538n22345gq2/

McGrath, M. J. (2007). School bullying: Tools for avoiding harm and liability. Thousand Oaks, CA: Corwin Press.

McLester, S. (2008). Top 10 tech trends. Technology \& Learning, 28(6), 14-18. http: / / www.techlearning.com/article/ ten-top-tech-trends / 44817

Nishina, A., Juvonen, J. \& Witkow, M. (2005). Sticks and stones may break my bones, but names will make me feel sick: The psychosocial, somatic, and scholastic consequences of peer harassment. Journal of Clinical Child \& Adolescent Psychology, 34(1), 37-48. http: / / dx.doi.org/10.1207/s15374424jccp3401_4

Özdamar, K. (2004). Paket programlarla istatistiksel veri analizi (Statistical analyses through package software). Eskisehir: Kaan Kitabevi.

Pallant, J. (2001). SPSS survival manual. Maidenhead, PA: Open University Press.

Patchin, J. W. \& Hinduja, S. (2006). Bullies move beyond the schoolyard: A preliminary look at cyberbullying. Youth Violence and Juvenile Justice, 4(2), 148-169. http:/ / yvj.sagepub.com/content/4/2/148.abstract

Roscigno, V. J., Lopez, S. H. \& Hodson, R. (2009). Supervisory bullying, status inequalities and organizational context. Social Forces, 87(3), 1561-1589.

http: / / muse.jhu.edu/login?uri=/ journals/social_forces/v087/87.3.roscigno.pdf 
Shariff, S. (2004). Keeping schools out of court: Legally defensible models of leadership. The Educational Forum, 68, 222-233. http: / / www.eric.ed.gov/PDFS / EJ724869.pdf

Shariff, S. (2008). Cyberbullying: Issues and solutions for the school, the classroom and the home. New York: Routledge.

Shore, K. (2009). Preventing bullying: nine ways to bully-proof your classroom. Education Digest: Essential Readings Condensed for Quick Review, 75(4), 39-44. http: / / www.eric.ed.gov/ERICWebPortal/ recordDetail?accno=EJ863928

Topçu, Ç., Erdur-Baker, Ö. \& Çapa-Aydin, Y. (2008). Examination of cyberbullying experiences among Turkish students from different school types. CyberPsychology E Behavior, 11(6), 643648. http:/ / www.liebertonline.com/doi/abs/10.1089/cpb.2007.0161

Walrave, M. \& Heirman, W. (2011). Cyberbullying: Predicting victimisation and perpetration. Children E Society, 25(1), 59-72. http:/ / onlinelibrary.wiley.com/doi/10.1111/j.10990860.2009.00260.x / full

Ward, D. A. \& Beck, W. L. (1990). Gender and dishonesty. The Journal of Social Psychology, 130(3), 333-339. http: / / www.tandfonline.com/doi/abs / 10.1080/00224545.1990.9924589

Willard, N. (2005). Educator's guide to cyberbullying: Addressing the harm caused by outline social cruelty. [viewed 16 Oct 2011]. http:/ / www.asdk12.org/MiddleLink/AVB/bully _topics/EducatorsGuide_Cyberbullying.pdf

Worthington, R. L. \& Whittaker, T. A. (2006). Scale development research: A content analysis and recommendations for best practices. The Counseling Psychologist, 34(6), 806-838. http: / tcp.sagepub.com/cgi/content/abstract/34/6/806

Ybarra, M. L., Mitchell, K. J., Wolak, J. \& Finkelhor D. (2006). Examining characteristics and associated distress related to Internet harassment: Findings from the second Youth Internet Survey. Pediatrics, 118(4), 1169-1177. http:// pediatrics.aappublications.org/content/118/4/e1169

Authors: Dr Yavuz Akbulut, Department of Computer Education and Instructional Technology, Anadolu University, 26470, Eskisehir, TURKEY.

Email: yavuzakbulut@anadolu.edu.tr

Yavuz Akbulut is an associate professor in the Department of Computer Education and Instructional Technology at Anadolu University. His research interests include ICT integration in tertiary education, human-computer interaction, cyber-psychology, behaviour and e-learning.

Dr Bahadir Eristi, Anadolu University Faculty of Education, Department of Educational Sciences, 26470, Eskisehir, TURKEY. Email: beristi@anadolu.edu.tr

Bahadir Eristi is an assistant professor in the Department of Educational Sciences at Anadolu University. He lists his research interests as teacher training, effectiveness of instructional strategies, teaching affective domain and values education.

Please cite as: Akbulut, Y. \& Eristi, B. (2011). Cyberbullying and victimisation among Turkish university students. Australasian Journal of Educational Technology, 27(7), 11551170. http: / / www.ascilite.org.au/ajet/ajet27/akbulut.html 